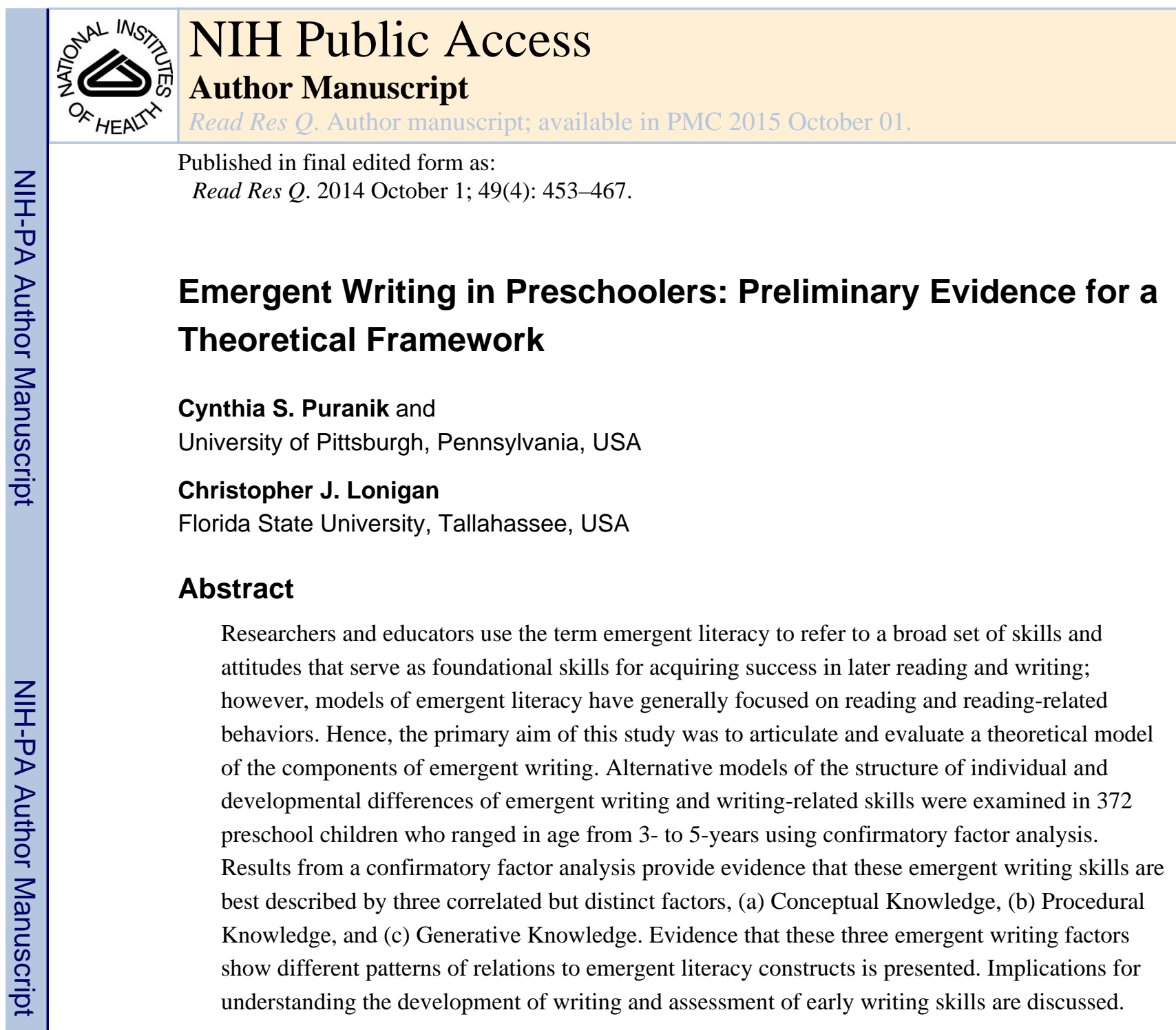

The acquisition of literacy skills is a fundamental goal of early schooling. Children need to learn the skills associated with both reading and writing, and these skills are used later in the educational process both to transmit and to evaluate knowledge. A large body of research has identified the key developmental processes of and precursors to skilled reading as well as problems in reading. Prior to school entry, many children acquire skills that are associated with reading development once formal reading instruction begins, including phonological processing skills, alphabet knowledge, concepts about print, and oral language skills.

Children with more of these skills in the preschool period learn to read faster and better than do children with fewer of these skills (e.g., Lonigan, Schatschneider, \& Westberg, 2008; Whitehurst \& Lonigan, 1998). From an early period in elementary school, reading skills are highly stable. That is children who are good readers tend to stay good readers, and children who are poor readers tend to stay poor readers (Duncan et al., 2007; Juel, 1988; Wagner, Torgesen, \& Rashotte, 1994; Wagner et al., 1997). Identification of early (or emergent) reading-related skills as well as their relative importance to the acquisition of reading has

Corresponding author: CYNTHIA S. PURANIK is an assistant professor in the Department of Communication Science and Disorders at University of Pittsburgh, PA, USA; cpuranik@ pitt.edu.

CHRISTOPHER J. LONIGAN is a distinguished research professor of Psychology and associate director of the Florida Center for Reading Research at Florida State University, Tallahassee, FL, USA; lonigan@psy.fsu.edu 
allowed refined understanding of reading development, allowed early identification of children at risk for educational difficulties, and promoted the development of early interventions for young children who are likely to experience difficulties learning to read.

Compared with the relatively large literature on the development and significance of emergent reading skills, the literature on the nature and development of emergent writing skills is less well developed. Both casual observations and studies reveal that many preschool-age children engage in some forms of writing. To date, however, much of the research concerning emergent writing has focused on only a few possible emergent writing skills. This research has demonstrated that preschool-age children are capable of writing letters of the alphabet (e.g., Clay, 1985; Hiebert, 1978, 1981; Puranik \& Lonigan, 2011), writing their names (e.g., Bloodgood, 1999; Levin, Both-De Vires, Aram, \& Bus, 2005), scribbling or drawing to communicate meaning (e.g., Levin \& Bus, 2003), and spelling single words (Bloodgood, 1999; Both-de Vries \& Bus, 2008; 2009; Puranik, Lonigan, \& Kim, 2011). The interconnections, developmental antecedents, and developmental consequences of these skills, however, have been less-well studied.

Puranik and Lonigan (2011) evaluated a broad set of preschool children's early writing skills, including letter writing, name-writing, spelling, knowledge about the conventions and functions of print, and descriptive use of writing. The results of this study revealed substantial increases in all writing skills across children from three through five years of age, including an increased number of correctly written letters, word spellings that progressed from use of the initial letter of a word to invented and correct spellings of words, and increased complexity of descriptive writing (e.g., linearity, segmentation, use of letters to represent words). Understanding the degree to which these different skills index the same or different processes associated with the development of writing will help in the identification of a coherent framework for studying young children's writing. Consequently, the primary goal of this study was to evaluate a comprehensive and conceptually coherent model of emergent writing to provide an organizational framework for the assessment of young children's writing that would allow a determination of the relative importance of different early writing skills and allow a refined understanding of early writing development.

\section{Conventional Writing Development}

Models of adults' and older children's writing are influenced by the framework proposed by Hayes and Flower (e.g., 1980, 1987). This framework consists of four cognitive processes, including planning, translating, reviewing, and revising. In an expansion of the simple view of reading, Juel, Griffith, and Gough (1986) proposed a "simple view of writing" that included two components, spelling and ideation. Whereas Juel et al. acknowledged that these two components of writing, like the two components of the simple view of reading, were complex processes, they highlighted the idea that spelling and decoding were likely to overlap substantially in their underlying sub-processes. This simple-view model was expanded and integrated with the Hayes and Flower model by Berninger et al. (2002) who proposed that writing involved text generation at different levels (i.e., word, sentence, discourse) supported by transcription processes (i.e., spelling, handwriting) and planning, reviewing, and revising processes. 
Berninger and her colleagues undertook a series of studies to investigate how the Hayes and Flower model might be used to explain writing development in children from first through ninth grades (e.g., Berninger, Yates, Cartwright, Rutberg, Remy, \& Abbott, 1992; see also Berninger \& Swanson, 1994, for a review). Results of these studies indicate that translation process in young children includes two subcomponents: transcription (i.e., the process of translating language into text) and text-generation (i.e., the process of translating thoughts into words). For skilled writers, transcription skills are executed with relative automaticity (e.g., Berninger, 1999; McCutchen, 2006), and a lack of automaticity in transcription skills negatively impacts children's ability to generate text (e.g., Bourdin \& Fayol, 1994; Graham, Berninger, Abbott, Abbott, \& Whitaker, 1997) as early as kindergarten (Puranik \& Al Otaiba, 2012).

As with reading skills, there is a moderate to large degree of cross-time consistency in children's writing from the early elementary school grades to later grades. Abbott, Berninger, and Fayol (2010) reported the results of a study in which 128 first grade children's writing and reading skills were assessed yearly through the fifth grade and 113 third grade children's writing and reading skills were assessed yearly through the seventh grade. Their results revealed stable individual differences across grades in children's handwriting, spelling, word reading, and text comprehension, with grade-to-grade withinskill path coefficients greater than 0.60 for spelling, written composition, word reading, and reading comprehension for most grades. Handwriting skills showed moderate stability across grades, with grade-to-grade within-skill path coefficients greater than 0.40 for most grades. There also were significant grade-to-grade cross-skill relations, suggesting reciprocal influences between and within writing and reading skills; however, the within-skill influences were stronger than the between-skill influences, indicating a degree of modularity between writing and reading skills.

Writing is a complex process that includes individual and developmental differences. One approach that has been used successfully in analyzing developmental and individual differences is the identification of the underlying dimensions that can account for performance across tasks. This approach has been used to understand the underlying dimensions of writing with grade-school populations (e.g., Guan, Ye, Wagner, \& Meng, 2013; Puranik, Lombardino, \& Altmann, 2008; Wagner et al., 2011). For example Wagner et al. (2011) reported that a model including macro-organization (i.e., use of topic sentence, idea organization), productivity (i.e., number of words used in writing and lexical diversity), complexity (i.e., mean length of the sentence and syntactic density), handwriting fluency (i.e., number of lowercase letters written in a timed task), and accuracy (i.e., spelling and punctuation) dimensions provided the best fit data from first- and fourth-grade children's composition. This approach was used in this study to examine the underlying structure of individual and developmental differences in the emergent writing of preschool children.

\section{Developmental Origins of Writing}

Similar to the development of reading, individual differences in children's writing skills are stable from early in elementary school. Consequently, understanding the precursors to conventional writing skills may allow a refined understanding of writing development by 
identifying skills that index future developmental outcomes that may signify early signs of risk for later problems, help elucidate the early reciprocal relations between early reading and early writing skills, and allow examination of the types of experiences that give rise to more or less early development of writing-related skills. Although several studies have investigated the concurrent relations among a few writing skills—often name writing and letter writing (e.g., Bloodgood, 1999; Diamond, Gerde, \& Powell, 2008)—or between early writing skills and later reading skills (e.g., Diamond \& Baroody, 2013; Molfese et al., 2011), few studies have examined longitudinal relations between measures of children's early writing skills in preschool and children's writing in elementary school. Hooper et al. (2010) reported that a measure of preschool children's writing concepts, which included name writing and identification of letters used in specific words predicted conventional writing skills in third, fourth, and fifth grades, and Dunsmuir and Blatchford (2004) reported that name writing at school entry predicted children's writing skill at age seven.

\section{Organizational Framework for the Construct of Emergent Writing}

Prior research (e.g., Bloodgood, 1999; Both-de Vries \& Bus, 2010) and theory (e.g., Ferreiro \& Teberosky, 1982; Lomax \& McGee, 1987; Tolchinsky, 2003) concerning emergent writing, research and theories concerning emergent literacy (e.g., Mason \& Stewart, 1990, Sénéchal, LeFevre, Smith-Chant, \& Colton, 2001; Whitehurst \& Lonigan, 1998), and models of writing in elementary school children (e.g., Hayes \& Berninger, 2010) suggest substantial interrelations between components of writing and reading domains. An organization framework that accounted for the covariation among specific emergent writing skills would allow better understanding of the nature of the developmental and individual differences of children's early writing skills. Considering the different types of emergent writing skills exhibited by children (e.g., Puranik \& Lonigan, 2011), we expected that emergent writing would have components similar and parallel to the components of emergent reading skills (i.e., knowledge of the functions and conventions of writing, coderelated knowledge) and components that would be unique to writing (i.e., skills related to the mechanics of writing and composing). Consequently, we hypothesized that three distinct but correlated dimensions would account for children's emergent writing skills. Although some theories concerning older children's writing include socio-cultural influences (e.g., Dyson, 2010; Hayes, 2006), our focus concerned the skills young children demonstrate while writing, not the reasons that children may use writing or the contexts in which writing is used. Consequently, our organizational framework did not include sociocultural factors.

\section{Conceptual knowledge}

Before children can read and write, they need to understand how printed language works. For example, they need to understand that writing is organized in straight lines or that one writes from left-to-right (in English). Therefore, the first skill domain represents children's understanding of the purpose of writing, knowledge about the functions of print, and knowledge pertaining to writing concepts (e.g., that print carries meaning and is a medium for communication; Ferreiro \& Teberosky, 1982; Fox \& Saracho, 1990; Lomax \& McGee, 1987; Mason, 1980; Tolchinsky-Landsman \& Levin, 1985). Children's knowledge of the functions and conventions of print are related to the development of skills both in emergent 
literacy domains and in conventional literacy domains (e.g., Whitehurst \& Lonigan, 1998), and it appears to be related to children's emergent writing such as letter writing and spelling (Puranik et al., 2011). From the larger set of concepts about print that are generally assessed in studies examining emergent literacy (e.g., Clay, 1985; Justice \& Ezell, 2001; Justice, Bowles, \& Skibbe, 2006), we restricted our focus to writing-related concepts. For example, we did not include skills pertaining to emergent reading, such as identifying the front and back of a book or identifying the first letter in a word. Writing-related skills in this domain included knowledge of the universal principles of print (e.g., knowledge of writing as a symbolic representational system, linearity of writing), concepts about writing (e.g., knowledge of units and means of writing), and functions of writing (e.g., purposes for which writing is used).

\section{Procedural knowledge}

Children become familiar with the general concepts of written language through exposure to print, but this knowledge does not necessarily translate into knowledge about the specific units of print such as letters and words (Robins \& Treiman, 2010). Hence, the second skill domain represents children's knowledge of the specific symbols and conventions involved in the production of writing. Borrowing from writing research with grade school children, writing-related skills within this domain included code-related knowledge such as alphabet knowledge, letter-writing skills, name-writing skill, and spelling. Knowledge of the alphabet (i.e., letter-name knowledge) is an important emergent reading skill (Whitehurst \& Lonigan, 1998), and knowing what letter-forms represent which letter names and letter sounds is the initial orthographic skill needed to write. Children's ability to identify letters was included because it has been shown to be a good predictor of conventional writing skills (Hooper et al., 2010). Furthermore, children's letter-name knowledge is associated with their children's letter-writing and spelling skills (Puranik et al., 2011). A child's name is often her or his first written word. Name writing was included because young children's name-writing abilities are a good indicator of their print-related and alphabet knowledge (e.g., Puranik et al., 2011; Welsch, Sullivan, \& Justice, 2003), and name writing may serve as the prototype for future writing (e.g., Bloodgood, 1999; Ferreiro \& Teberosky, 1982; Levin et al., 2005). Finally, letter writing and spelling was included because transcription skills like letter writing and spelling constrain children's abilities to compose text beyond the word level. Elementary school children's spelling and letter-writing fluency are among the best predictors of the length and quality of their written compositions (e.g., Graham et al., 1997; Puranik \& Al Otaiba, 2012).

\section{Generative knowledge}

The third skill domain represents children's emerging ability to compose phrases and sentences in their writing. Studies conducted by Berninger and colleagues indicate that a functional writing system at the translation level draws upon and integrates different levels of language at the word, sentences, and discourse level (Berninger \& Swanson, 1994; Berninger, et al., 1992). Even after children become familiar with print and letters, it does not necessarily mean that they understand the symbolic and representational significance of those letters to convey meaning (Bialystok, 1995). Understanding the symbolic representational significance of letters to eventually convey meaning takes time and only 
when children grasp this knowledge can they generate text beyond the word level (e.g., phrases, sentences) to express ideas. Skills in the generative knowledge included children's abilities to convey meaning through writing beyond the single-word level. Although the majority of preschool-age children would not be expected to produce even moderately skilled writing, examination of their abilities to compose to convey meaning could be an excellent reflection of how they integrate and use their procedural and conceptual knowledge such as knowledge of letters, universal and language-specific properties of writing (e.g., linearity, left-to-right orientation), and print-related knowledge (e.g., specific letter strings represent specific words, words are separated by spaces) to represent language structures and convey meaning.

\section{Current Study}

The primary goal of this study was to articulate and evaluate an organizational framework for the assessment of young children's writing. To that end, we evaluated how well the three hypothesized domains of emergent writing accounted for preschool children's performance on writing-related tasks designed to index these domains. Confirmatory factor analysis (CFA) was used to compare the adequacy of the hypothesized three-factor model to four alternative models. The alternative models included a one-factor general writing abilities model and three two-factor models that represented the alternative structuring of the three domains in the three-factor model. Because writing skills are developing over the preschool period, the degree to which the same model accounted for children's performance on writing tasks across the preschool period was tested. Finally, because three domains were hypothesized to represent distinct underlying components of writing, it was expected that the different dimensions would have differential relations to general cognitive abilities, language skills, and emergent literacy skills. Specifically, it was expected that the two dimensions reflecting children's procedural and generative knowledge of writing would relate more strongly to other measures of print knowledge and phonological awareness than to measures of general cognitive ability or language skills because these writing subskills are assumed to take advantage of the same code-related skills as decoding (McBride-Chang, 1998).

\section{Method}

\section{Participants}

Participants for this study were recruited from 34 different private and public and private preschool centers in a moderately sized city in north Florida. The sample consisted of 372 children who ranged in age from 36 to 71 months $(M=57.06$ months, $S D=5.73)$. There were 202 boys and 170 girls. No specific exclusionary criteria were used; however the child's classroom teacher was consulted to ensure that none of the children had significant conditions or delays that would make it difficult for a child to provide meaningful responses to the assessments. More than half of the children in the sample were white (54\%), and the remainder of the sample was Black/African American (35.9\%), Hispanic (2.7\%), Asian $2.7 \%$, or other/multiple ethnicity (4.7\%). Children's parents were asked to complete a questionnaire that included information about family socioeconomic status (SES; i.e., education, income). Fifty-one percent of the sample completed and returned questionnaires. 
Based on these responses, parental education in the sample was normally distributed and ranged from "did not complete high school" to "postdoctoral degree." The median level of education reported was in the range of "completed some college" to "completed AA degree." Only $10 \%$ of the sample reported completing a BA or above, and less than $10 \%$ reported less than a high school diploma or GED. Median reported income was in the $\$ 31,000$ to $\$ 40,000$ range.

\section{Preschool Centers}

Procedures and routines at the participating preschool centers were not systematically observed. The curricula at each participating centers were generally designed to promote social and interpersonal skills and to introduce children to a variety of educational concepts such as numbers, letters, nursery rhymes, songs, and story books. Common activities at these centers included free play, center time, small-group arts and crafts projects, story time, music centers, and small group instruction.

\section{Measures}

Conceptual knowledge-Three subtests assessed children's conceptual knowledge about writing. Three items measured Universal Principles of Print $(a=0.52)$ and involved questions about the understanding of print (which one shows the name of the book? which one can people read? which one is the correct way to write milk?). Six items measured Concepts about Writing $(\alpha=0.73)$ and involved conventions for recording written language (Which one is a letter? Which one is a sentence? Which one is a word? Which one is a number?) and knowledge regarding utilization of writing utensils (Which is the best way to hold a pencil? Which one is the wrong way to hold a pencil?). For both the Universal Print Principles and Concepts about Writing subtests, children were shown a set of four pictures and had to point to the picture that corresponded to the correct answer for the question. Ten items measured Functions of Print $(a=0.73)$. These items assessed knowledge of the ways in which writing and writing-related materials are used (e.g., identify a newspaper, tell what people do with a newspaper). On the Functions of Print subscale, half of the items required children to answer specific questions verbally (e.g., what do people do with a newspaper?) in addition to pointing to a correct answer from among four pictures. All items on these three subtests were scored as either correct or incorrect.

Procedural knowledge—Four subtests measured domains associated with children's procedural knowledge about writing. On the Identify Letters subtest $(a=0.92)$, children were shown upper-case letters printed on cards and asked to name the letter. Letters were presented to children in a fixed random order. On the Write Letters subtest $(\alpha=0.93)$, children were asked to write each of 10 letters named by the examiner. Both the Identify Letters and the Write Letters subtests used the same 10 letters (B, D, S, T, O, A, H, K, M, C). The number of letters was based on recommendations made by Mason and Stewart (1990). The specific letters chosen were a mix of easy and difficult letters based on research examining the development of letter-name knowledge and letter writing in preschool children (e.g., Justice, Pence, Bowles, \& Wiggins, 2006; Phillips, et al., 2012; Puranik, Petscher, \& Lonigan, 2012). The Write Name subtest $(\alpha=0.92)$, required children to write 
their names using paper and pencil provided. Finally, the Write Words subtest $(a=0.96)$ required children to write six common words (mat, bed, duck, cat, fell, hen).

Items for the Identify Letters subtest were scored as correct or incorrect. Scoring for the Write Letters subtest depended on how well or how poorly the letter was formed (i.e., $0=$ no response or illegible letter; 1 = reversals or poorly formed letter; 2 = well-formed and legible letter), and credit was given regardless of case-although most children wrote with uppercase letters. The Write Name subtest was scored on a 9-point scale based on writing features identified in previous studies in English-speaking preschoolers and other languages such as Hebrew and Spanish and based on theoretical accounts of writing development, particularly name writing (e.g., Ferreiro \& Teberosky, 1982). Children were given 1 point for each of the following writing features: (a) linearity (writing units organized in straight lines), (b) segmentation (writing contained at least two distinguishable/separate units [e.g., circles, dots, letters, or separate letter-like characters]), (c) simple characters (units were simple forms including dots, circles, and short vertical or horizontal lines), (d) left-to-right orientation (e) complex characters (units were not simple and include pseudo and real letters, (f) random letters (g) first letter of name, (h) writes more than half of the letters contained in their first name, and (i) correctly spelling of first name.

The Write Words subtest was scored on a 7-point scale based on a modified version of Tangel and Blachman's (1992) spelling rubric in which children are given points for the number of phonemes they represent in writing. For example, preschoolers frequently spell words using one letter, generally the first letter of a word because they believe that it is the legitimate written form for the whole word (Ferreiro, 1984), so in the scoring system used, children were given credit for writing the first letter. The scoring system used (as opposed to a dichotomous scoring system) was able to capture children's developing knowledge of spelling. A total score was obtained by summing the individual word scores. The maximum possible score for the Write Words task was 42.

Generative knowledge-Two tasks were used to measure children's generative knowledge about writing and to assess children's writing abilities beyond the single-word level. On the Picture Description subtest (2 items; [a] Clown eating a banana, and [b] Girl bathing a dog), children were shown a picture and asked to write a description of the picture using paper and pencil provided. On the Sentence Retell subtest ( 2 items; [a] The boy is wearing a red cap, [b] She is making the bed), children were asked to repeat orally a short sentence spoken by the examiner and then to write the sentence using paper and pencil provided. These close-ended tasks were chosen with the idea that describing pictures and then writing and repeating a sentence and then writing it would be easier for preschool children than an open-ended task such as spontaneous writing. In pilot work, preschool children had significant difficulty completing a spontaneous writing task; however, most children attempted to complete the close-ended writing tasks. These tasks also had the advantage that the output was controlled, which made them easier to score than a spontaneous writing sample for which the output could vary considerably between children.

In scoring for the Picture Description and Sentence Retell subtest, one point was awarded for the presence of each of seven features (i.e., linearity, segmentation, presence of simple 
units, left-to-right orientation, presence of complex characters, random letters, invented spelling). Because preschool children are not yet writing conventionally, a scoring system that captures their knowledge of writing needed to be used. The features identified for this study was based on previous research with preschool children. For each task, a total score was obtained by summing the individual feature scores.

Scoring reliability for writing tasks-The three conceptual knowledge tasks and two procedural knowledge tasks- identify letters and write letters tasks were double-scored by trained research assistants. Scores were also entered by two research assistants to reduce data entry errors. The first author and a trained graduate assistant scored the Write Name, Write Words, Picture Description, and Sentence Retell subtests. To provide an estimate of scoring reliability, a random 30 percent of the responses were independently coded by each rater. Inter-rater reliability ranged from $93 \%$ to $100 \%$. Scoring discrepancies were resolved through discussion, and the final score entered was the one decided by two raters.

Test of Preschool Early Literacy (TOPEL)—The TOPEL (Lonigan, Wagner, Torgesen, \& Rashotte, 2007) includes three subtests: Definitional Vocabulary, Phonological Awareness, and Print Knowledge. The Definitional Vocabulary subtest measures children's single word spoken vocabulary and their ability to formulate definitions for words. The Phonological Awareness subtest includes 27 multiple-choice and free-response items along the developmental continuum of phonological awareness from word awareness to phonemic awareness. Children are required to perform both blending (putting sounds together to form a new word) and elision (removing sounds from a word to form a new word). Training items are included to ensure the child understood the task. The Definitional Vocabulary subtest contains 35 items and targets the child's oral vocabulary and ability to define single words. The child is asked to identify a picture and then describe an important characteristic, attribute, or function. The Print Knowledge subtest contains 36 items to assess familiarity with writing conventions and alphabet knowledge. To assess knowledge of written language conventions, the child is asked to identify various aspects of print and identify letters and words within a field of four pictures. To assess alphabet knowledge, the child is asked to identify, name, and produce the phoneme associated with various letters. According to the test manual, internal consistency reliabilities for the three subtests ranges from 0.86 to 0.96 for 3- to 5-year-olds, and test-retest reliability over a one- to two-week period ranges from 0.81 to 0.89 . Each subtest also has good criterion predictive validity, with high correlations ( $r \mathrm{~s} \geq 0.59)$ between the subtests and other measures of similar constructs.

General cognitive abilities-To provide an estimate of cognitive abilities, children completed the Block Design subtest of the Weschler Preschool and Primary Intelligence Scale-Third Edition (WPPSI-III; Weschler, 2002). This subtest has been used in previous studies and is particularly useful in measuring nonverbal cognitive abilities because it does not require a verbal response (e.g., Stothard, Snowling, Bishop, Chipchase, \& Kaplan, 1998). On the Block Design subtest, children are required to re-create a design using blocks while viewing a constructed model or a picture in a stimulus book within a specified time limit. During a test the child is initially provided with solid blocks and is asked to duplicate a model design provided by the examiner. The models grow in complexity as the test 
progresses and the task becomes more challenging as the examiner begins to introduce blocks with two-sided colors. The subtest is discontinued when a child provides three consecutive incorrect responses. This subtest has strong reliability and significant correlations with the Performance IQ and the Full Scale IQ scores derived from the WPPSIIII. Criterion validity for the WPPSI-R is supported by high correlations with other instruments measuring cognitive abilities (e.g., Differential Ability Scales [DAS]; $r=0.69$ ).

\section{Procedure}

After receiving informed consent from the parents of participating children, trained research assistants tested children individually at their respective preschools. All research assistants had experience working with young children and received training in administering the protocol. All data were collected in the spring of the school year and completed within a 2month period. Assessments were conducted in a quiet room or area of the preschool. The writing assessment was typically completed in one session, lasting 20 to 45 minutes. Children were given breaks as needed. Children completed the TOPEL and Block Design subtest as part of a larger study; these measures were completed during a different assessment session than the one in which the writing assessment was completed. All tasks within a session were administered in the same order to all children, but some children completed the writing assessment first and some children completed the TOPEL and Block Design subtest first.

\section{Results}

\section{Descriptive Statistics}

Children's mean scaled and standard scores on the Block Design subtest of the WPPSI (9.21; $S D=2.84)$ and the Definitional Vocabulary $(96.85 ; S D=14.01)$, Phonological Awareness (98.48; $S D=15.82)$, and Print Knowledge (102.34; $S D=14.07)$ subtests of the TOPEL were in the average range. Descriptive statistics for all writing and writing-related measures are shown in Table 1. As seen in the table, there was large variability in children's writing abilities in terms of raw scores. Approximately $75 \%$ of children were able to name at least half of the letters assessed, and $43 \%$ of children were able to recognize all the letters in the Identify Letters task. Only a small number of children (4\%) were not able to recognize any of the letters assessed on the Identify Letters task. In contrast, only $13 \%$ of the children were able to write all the letters of the alphabet, and approximately $13 \%$ of the children were not able to write any letters of the alphabet. As expected, children had a high degree of knowledge regarding their first names. Approximately $81 \%$ of the children were able to write at least the first letters of their names, and 54\% of the children were able to spell their first names correctly. Across the six words, the percentage of children who were able to write at least the first or last letter for all words in the Write Words task ranged from 25 to $38 \%$. The majority of younger children had difficulty with the composing tasks; however, most of them attempted to convey meaning through scribbling or writing random letters.

\section{Evaluation of Measurement Models}

Theoretically plausible alternative models of children's performance on the emergent writing-related tasks were evaluated using CFA in EQS 6.1 (Bentler, 2006). We evaluated 
the fit of models consisting of the possible one-, two-, and three-factor combinations of the groupings of emergent writing tasks (i.e., conceptual knowledge, procedural knowledge, and generative knowledge). To avoid confounding differences in skill with variation due to development, all variables were age-standardized by regressing raw scores from each task onto chronological age to remove variance due to age before conducting the CFAs. CFAs were conducted on this age-corrected raw data using maximum likelihood estimation with the Satorra-Bentler scaled chi-square $\left(\mathrm{S}-\mathrm{B} \chi^{2}\right)$ and adjustments to the standard errors to account for nonnormality in model fit statistics and significance testing (Bentler \& Dudgeon, 1996).

Inspection of the distributional properties of the different emergent writing task variables revealed some mild to moderate departures from normality. Because of concerns that even the S-B $\chi^{2}$ may not yield unbiased tests of model misspecification with non-normal distributions and smaller samples (Curran, West, \& Finch, 1996), data points that were significant outliers were set equal to the highest value of non-outlier cases (Tabachnick \& Fidell, 2007). This transformation substantially improved the distribution of the variables (i.e., reducing skew and kurtosis to nonsignificant levels). Because the results of CFA with these transformed data were nearly identical to the results of CFA with untransformed data, indicating that the mild to moderate departures in normality in the untransformed data would have limited impact on the results and conclusions, analyses using the untransformed data are reported.

Preliminary analyses of models and inspection of modification indices indicated that the addition of two correlated residuals substantially improved model fits. These model parameters included correlations between residuals for the two picture description tasks and correlations between the residuals for the identify letters task and the write letters task. All subsequent models included these correlated residuals. Whereas inclusion of these parameters improved model fits because they accounted for systematic method or content covariance, they did not alter the structural relations of the models (i.e., structural results were the same with or without the correlated residuals).

Fit indices for the different models are shown in Table 2. Both the three-factor model and the two-factor model in which Conceptual Knowledge and Procedural Knowledge factors were combined into a single-factor provided adequate fits to the data; however, the $\chi^{2}$ difference test revealed that the two-factor model with the combined Conceptual Knowledge and Procedural Knowledge factor yielded a significantly worse fit to the data than did the three-factor model. Both of the other two-factor models and the one-factor model also yielded significantly worse fits to the data than did the three-factor model. Consequently, the three-factor model provided the best fit to the data.

Parameter values for the three-factor model for the combined sample are shown in Figure 1. All paths in the model were significant at $p<0.001$. Factors accounted for nontrivial amounts of the variance in children's scores on the different emergent writing tasks, with the Conceptual Knowledge factor accounting for between 30 and 54\% of the variance in individual tasks, the Procedural Knowledge factor accounting for between 41 and $71 \%$ of the variance in individual tasks, and the Generative Knowledge factor accounting for 
between 18 and $92 \%$ of the variance in individual tasks. The correlation between Conceptual Knowledge and Procedural Knowledge factors was strong whereas the correlations between Conceptual Knowledge and Generative Knowledge factors and between Procedural Knowledge and Generative Knowledge factors were moderate.

Comparison of model fit across age-Because of the wide age-range of the children in the sample, multi-sample CFA was used to examine whether the same three-factor model fit the data for younger and older children in the sample. Children were divided into an older group (older than 58 months of age; $n=176$ ) and a younger group (younger than 59 months of age; $n=196$ ) based on a median age split. Descriptive statistics on the writing and writing-related measures for the older and younger groups are shown in Table 1. Older children scored significantly higher than did the younger children on all writing and writingrelated measures $(p s<0.05)$ except the Picture Description $(p s>0.10)$ and Sentence Retell $(p s>0.40)$ measures.

A multi-sample model with none of the parameters constrained to equality across age groups served as the basis for comparing the effects of constraining parameters across age groups to equality. A summary of these analyses is shown in Table 3. The unconstrained multi-sample model provided a good fit to the data, confirming that the three-factor model worked well across both age groups. In the hierarchy of invariance constraints, neither constraining the correlations between factors and between residuals to equality across groups, $\chi^{2}$ difference $(5, N=372)=5.13, p>0.10$, nor constraining the factor loadings to equality across groups, $\chi^{2}$ difference $(16, N=372)=14.16, p>0.10$, resulted in a significant reduction in model fit from the fully unconstrained model. However, when all of the residuals were constrained to equality across groups, the model provided a significantly worse fit to the data than did the fully unconstrained model, $\chi^{2}$ difference $(27, N=372)=82.53, p<0.001$. Releasing three of these invariance constraints (i.e., the residuals for the Identify Letters task, the Write Letters task, and the second trial of the picture description task), resulted in a model that fit the data as well as the fully unconstrained model, $\chi^{2}$ difference $(24, N=372)=22.64, p$ > 0.10 . Therefore, whereas the same three-factor model provided an adequate fit to the structure of the data for both younger and older children, the degree to which scores on three variables were accounted for by the model varied between younger and older children.

\section{Associations of Emergent Writing Factors with Measures of Early Literacy}

To evaluate the degree to which each of the emergent writing factors were associated with other aspects of emergent literacy skills, correlations between the factors and the three subtest scores of the TOPEL as well as the Block Design subtest of the WPPSI were computed. As can be seen in Table 4, both the Conceptual Knowledge and Procedural Knowledge factors were moderately to highly correlated with all four measures; however, the Generative Knowledge factor was only correlated with the Print Knowledge and Phonological Awareness subtests of the TOPEL. For the Conceptual Knowledge and Procedural Knowledge factors, the Block Design subtest was a significantly weaker correlate than were the Definitional Vocabulary, Phonological Awareness, and Print Knowledge subtests of the TOPEL ( $p s<0.001$ ). The three subtests of the TOPEL were equally correlated with the Conceptual Knowledge factor, whereas the Print Knowledge 
subtest of the TOPEL was more strongly correlated with the Procedural Knowledge factor than were the Definitional Vocabulary and Phonological Awareness subtests $(p s<0.001$ ), and the Phonological Awareness subtest was more highly correlated with this factor than was the Definitional Vocabulary subtest $(p<0.03)$. The Print Knowledge subtest of the TOPEL was more highly correlated with the Generative Knowledge factor than the other two TOPEL subtests and the Block Design subtest $(p s<0.04)$.

Structural models were used to determine the degree of unique variance accounted for in each factor by the TOPEL and Block Design subtests. Semi-partial correlations from these models are shown in Table 4. The Block Design, Definitional Vocabulary, and Print Knowledge subtests predicted unique variance in the Conceptual Knowledge factor $\left(R^{2}=\right.$ 0.32). The Block Design and Print Knowledge subtests predicted unique variance in the Procedural Knowledge factor $\left(R^{2}=0.42\right)$. Only Print Knowledge predicted unique variance in the Generative Knowledge factor $\left(R^{2}=0.03\right)$.

\section{Discussion}

The aims of this study were to determine the underlying structure of preschool children's emergent writing skills and to determine the degree of common and unique overlap of the dimensions of emergent writing with general cognitive abilities, language skills, and emergent literacy skills. The results demonstrated that the hypothesized three-factor model of emergent writing skills, consisting of procedural knowledge, conceptual knowledge, and generative knowledge domains, best described children's performance on writing-related measures. The same three-factor model accounted for both older and younger children's emergent writing skills, despite significant differences in the absolute levels of skills in writing-related tasks between older and younger children. Additionally, the three dimensions underlying children's emergent writing skills had distinct patterns of relations with measures of general abilities and emergent literacy skills. The results of this study have implications for understanding the development, development origins, and developmental significance of emergent writing skills.

Prior studies of children's early writing have typically focused on a limited number of children's emergent writing skills-often only one or two. Results of this study revealed that there is substantial overlap between some emergent writing skills, and that different writingrelated skills group into distinct sets of skills. Knowledge of the principles, concepts, and functions of writing represent children's knowledge concerning the purposes and basic structure of writing. Knowledge of the alphabet, including identification of letters and the ability to write letters, name writing, and spelling of simple words represent children's knowledge and skills concerning the mechanics of writing. The ability to produce writing beyond the letter or word level represents an ability that is separate from the mechanics of writing. With the exception of the picture description tasks, each of the factors accounted for moderate to large amounts of the variance in the individual emergent writing skills, indicating the three-factor model adequately accounted for children's emergent writing skills. 
The unique pattern of relations between the three dimensions of emergent writing and measures of general cognitive skills, language skills, and code-related skills provides additional support for the distinction between three domains of emergent writing skills. The Conceptual Knowledge factor was broadly associated with all of the non-writing skills. Children's general cognitive abilities, language skills, and print knowledge were each uniquely related to level of skill in this domain. This finding suggests that the developmental influences for these skills are, in part, those that promote broad cognitive development, like high-quality environments with significant exposure to language and print. The Procedural Knowledge factor also was broadly associated with the non-writing skills, but only general cognitive abilities and print knowledge were uniquely related to level of skill in this domain. This finding suggests that the development origins of these skills are primarily those that affect children's developing knowledge about the alphabetic code. The Generative Knowledge factor was associated with only the code-related measures of emergent literacy, and only print knowledge was uniquely related to level of skill in this domain. The amount of variance accounted for on the Generative Knowledge factor was small (i.e., 3\%), suggesting that the developmental origins of skills in this domain are largely different than those associated with the other domains of emergent writing.

A model of emergent writing skills consisting of three separate domains fits well with the levels of language framework proposed for conventional writing skills (e.g., Abbott, et al., 2010; Whitaker, Berninger, Johnston, \& Swanson, 1994). Between models, the procedural knowledge domain of emergent writing corresponds to the transcription component in the model for older children, which reflects word-level writing, and the generative knowledge domain of emergent writing corresponds to the text-generation component in the model for older children. For older children, letter-writing fluency and spelling are two important transcription skills that support text generation and written composition (e.g., Graham, et al., 1997; Puranik \& Al Otaiba, 2012). For preschool-age children, knowledge of the alphabet, the ability to write letters, and the ability to use this knowledge in the generation of written words (e.g., writing names, spelling simple CVC words) involves the emergence of the skills necessary to translate concepts into symbols for written language. Older children's ability to generate ideas in writing is limited by the working memory demands of transcription (Berninger \& Swanson, 1994; Hayes \& Berninger, 2010). It is possible that similar processes limit preschool children's ability to write beyond the word level, leading to performance in the generative knowledge domain-even when the output of writing is controlled by providing children with the idea to be written.

To date, most studies concerning emergent writing skills in young children have been observational-descriptive (e.g., Ferreiro \& Teberosky, 1982; Tolchinsky, 2003) or have focused on either the concurrent relations among a few writing skills (e.g., Bloodgood, 1999; Diamond et al., 2008; Molfese, Beswick, Molnar, \& Jacobi-Vessels, 2006) or between one or two writing skills and later reading skills (e.g., Diamond \& Baroody, 2013; Molfese et al., 2011). Only a few studies to date have examined longitudinal relations between emergent writing skills and later, conventional writing skills (e.g., Dunsmuir \& Blatchford, 2004; Hooper et al., 2010). Even these studies, however, have not included more than one or two emergent writing skills. Longitudinal predictive studies are ultimately needed to advance an understanding of the developmental significance of emergent writing for later 
writing and reading development. The organization framework provided by the results of this study may be a useful heuristic under which to understand findings from such studies. Similarly, this organization framework may be useful in attempts to understand the developmental origins of emergent writing skills.

It seems unlikely that each of the three factors will be uniquely related to later writing skills. For instance, it is probable that children's conceptual knowledge about writing is a reflection of children's exposure to writing in their environments and children's developing interests in writing. Although higher scores on measures in this domain are likely associated with the types of experiences that promote children's knowledge about the mechanics of writing (e.g., letter names, letter writing, letter-sound correspondence) and will, therefore, be associated with high scores on tasks within the procedural knowledge domain, this knowledge is not likely to lead directly to higher levels of skills associated with later transcription. For instance, in the Hooper et al. (2010) study, children's knowledge of writing concepts was not a significant predictor in multivariate analyses that included measures of decoding and language skills. Similarly, in the emergent literacy domain, measures of children's concepts about print typically do not predict reading outcomes once measures of direct skills (e.g., phonological awareness, alphabet knowledge) are included in prediction models (e.g., Whitehurst \& Lonigan, 1998).

As noted above, children's procedural knowledge about writing is most likely to be related to their later transcription skills. In fact, most skills associated with this domain appear to represent the early emergence of transcription skills, although most heavily influenced by alphabet knowledge. Further study of skills in this domain may provide information on how children's writing changes between a prephonological stage and a phonological stage (e.g., Treiman \& Kessler, 2013). Finally, additional studies are needed to understand the developmental significance of children's generative knowledge. Whereas many young children attempt to write spontaneously beyond the word level, and systematic assessments demonstrated that young children do have the capacity to write beyond the word level in a form approaching conventional writing (e.g., Bloodgood, 1999; Puranik \& Lonigan, 2011), whether such skills reflect something related to later text generation or an underlying cognitive capacity, like working memory, requires further study. The fact that generative knowledge was only weakly related to procedural knowledge indicates the ability to produce writing beyond the word level represents skills other than those associated with transcription.

\section{Limitations}

Despite the strengths of this study, which include a relatively large sample of children, measurement of a broad array of children's emergent writing skills, and a hypothesis-driven analytic approach, there were a number of limitations to the study worth noting. First, a small number of items were used for some tasks measuring conceptual knowledge (e.g., universal principles, concepts about writing), and perhaps the knowledge assessed was not comprehensive or representative of the knowledge possessed by young children in these two skill areas. Second, internal consistencies for the conceptual knowledge tasks were lower than desirable, most likely reflecting of the small number of items used to measure these 
skills. Despite these lower internal consistency estimates, however, the tasks loaded strongly on the Conceptual Knowledge factor. Expanding the number of these items will both improve the reliability of these tasks and increase the content coverage. Third, several of the younger children were unable to complete the generative knowledge tasks, resulting in floor effects on these measures for younger children. The scoring system used, however, was able to capture knowledge about early generative knowledge skills (e.g., linearity, left-to-right orientation) that children possess even when they are unable to write conventionally. The fact that the same three-factor model fit the data for younger and older children indicates that floor effects were not a major limitation. Fourth, none of the tasks directly assessed children's letter-sound knowledge. Letter-sound knowledge was not included because preschool children are usually more knowledgeable about letter names and letter shapes than letter sounds (Levin, Shatil-Carmon, \& Asif-Rave, 2006; Treiman, Kessler, \& Pollo, 2006). However, inclusion of such measures is likely an important step for understanding the role of phonological processes in emergent writing. Finally, these data were cross-sectional. Consequently, although the analyses address questions of the dimensionality of emergent writing, they cannot address causal relations between these dimensions. As noted above, longitudinal studies are needed both to understand within and between domain influences and to understand the developmental significance of skills in each domain on later conventional writing skills.

\section{Summary and Conclusions}

Children's acquisition of literacy skills, including reading and writing, represents a foundational educational milestone. Compared with the amount of research on children's emergent literacy skills, however, there is relatively less research on children's emergent writing skills, and most extant studies have focused on only a few emergent writing skills. This study provided support for a model of emergent writing that consists of skills in three domains. Conceptual knowledge skills represent knowledge about the conventions and functions of writing. Procedural knowledge skills represent knowledge and abilities about the mechanics of writing at the letter and word levels. Generative knowledge skills represent knowledge and abilities about the production of writing beyond the word level. Results indicated that this three-factor model accounted for children's performance across a wide array of emergent writing tasks better than alternative models, and that the same three-factor model fit data from older and younger preschool children. Distinct patterns of relations between the factors and other abilities provided additional support for the model and suggested different developmental origins of skills in these three domains. Future longitudinal research is needed to elucidate the development significance of skills in these domains for the acquisition of later, conventional writing skills.

\section{Acknowledgments}

Support for carrying out this research was provided in part by grant P50 HD052120 from the National Institute of Child Health and Human Development, and by a Postdoctoral Training Grant R305B050032 and grant R305A080488 from the Institute of Education Sciences. The opinions expressed are those of the authors and do not represent views of the funding agencies. 


\section{References}

Abbott RD, Berninger VW, Fayol M. Longitudinal relationships of levels of language in writing and between writing and reading in grades 1 to 7. Journal of Educational Psychology. 2010; 102(2): 281-298.10.1037/a0019318

Bentler, PM. EQS Structural Equations Program Manual. Encino, CA: Multivariate Software; 2006.

Bentler PM, Dudgeon P. Covariance structure analysis: Statistical practice, theory, and directions. Annual Review of Psychology. 1996; 47:563-592.10.1146/annurev.psych.47.1.563

Berninger VW. Coordinating transcription and text generation in working memory during composing: Automatic and constructive processes. Learning Disability Quarterly. 1999; 22(2):99_ 112.10.2307/1511269

Berninger, VW.; Swanson, HL. Modifying Hayes and Flower's model of skilled writing to explain beginning and developing writing. In: Butterfield, E., editor. Children's writing: Toward a process theory of development of skilled writing. Greenwich, CT: JAI Press; 1994. p. 57-81.

Berninger VW, Vaughan K, Abbott RD, Begay K, Byrd KC, Curtin G. Teaching spelling and composition alone and together: Implications for the simple view of writing. Journal of Educational Psychology. 2002; 94(2):291-304.10.1037/0022-0663.94.2.291

Berninger VW, Yates C, Cartwright A, Rutberg J, Remy E, Abbott RD. Lower-level developmental skills in beginning writing. Reading and Writing: An Interdisciplinary Journal. 1992; 4(3):257280.10.1007/BF01027151

Bialystok E. Making concepts of print symbolic: Understanding how writing represents language. First Language. 1995; 15(45):317-338.10.1177/014272379501504504

Bloodgood JW. What's in a name? Children's name writing and literacy acquisition. Reading Research Quarterly. 1999; 34(3):342-367.10.1598/RRQ.34.3.5

Both- de Vries A, Bus AG. Name writing: A first step to phonetic writing? Literacy Teaching and Learning. 2008; 12(2):37-55.

Both- de Vries A, Bus AG. The proper name as starting point for basic reading skills. Reading and Writing: An Interdisciplinary Journal. 2009; 23(2):173-187.

Bourdin B, Fayol M. Is written language production more difficult than oral language production: A working-memory approach. International Journal of Psychology. 1994; 29(5):591$620.10 .1080 / 00207599408248175$

Clay, M. Early detection of reading difficulties. 3. Portsmouth, NH: Heinemann; 1985.

Curran PJ, West SG, Finch JF. The robustness of test statistics to nonnormality and specification error in confirmatory factor analyses. Psychological Methods. 1996; 1:16-29.10.1037/1082-989X. 1.1 .16

Diamond KE, Baroody AE. Associations among name writing and alphabetic skills in prekindergarten and kindergarten children at risk of school failure. Journal of Early Intervention. 2013; 35:20 39.10.1177/1053815113499611

Diamond KE, Gerde HK, Powell DR. Development in early literacy skills during the pre-kindergarten year in Head Start: Relations between growth in children writing and understanding of letters. Early Childhood Research Quarterly. 2008; 23(4):467-478.10.1016/j.ecresq.2008.05.002

Duncan GJ, Dowsett CJ, Claessens A, Magnuson K, Huston AC. School readiness and later achievement. Developmental Psychology. 2007; 43(6):1428-1446.10.1037/0012-1649.43.6.1428 [PubMed: 18020822]

Dunsmuir S, Blatchford P. Predictors of writing competence in 4- to 7-year-old children. The British Journal of Educational Psychology. 2004; 74(3):461-483.10.1348/0007099041552323 [PubMed: 15296550]

Dyson, AH. The cultural and symbolic "begats" of child composing: Textual play and community membership. In: Saracho, ON.; Spodek, B., editors. Contemporary perspectives on language and cultural diversity in early childhood education. Charlotte, NC: Information Age Publishing; 2010. p. 191-211.

Ferreiro, E. The underlying logic of literacy development. In: Goelman, H.; Oberg, A.; Smith, F., editors. Awakening to Literacy. Exeter, NH: Heinemann; 1984. p. 154-173. 
Ferreiro, E.; Teberosky, A. Literacy before schooling. Exeter, NH: Heinemann; 1982.

Fox BJ, Saracho ON. Emergent writing: Young children solving the written language puzzle. Early Child Development and Care. 1990; 56:81-90.10.1080/0300443900560108

Gough PB, Tunmer WE. Decoding, reading, and reading disability. Remedial and Special Education. 1986; 7:6-10.10.1177/074193258600700104

Graham S, Berninger VW, Abbott RD, Abbott S, Whitaker D. The role of mechanics in composing of elementary school students: A new methodological approach. Journal of Educational Psychology. 1997; 89:170-182.10.1037/0022-0663.89.1.170

Guan CQ, Ye F, Wagner RK, Meng W. Developmental and individual differences in Chinese writing. Reading and Writing: An Interdisciplinary Journal. Advance online publication. 201210.1007/ s11145-012-9405-4

Hayes, JR. New directions in writing theory. In: MacArthur, CA.; Graham, S.; Fitzgerald, J., editors. Handbook of writing research. New York, NY: Guilford Press; 2006. p. 28-40.

Hayes, JR.; Berninger, VW. Relationships between idea generation and transcription: How act of writing shapes what children write. In: Brazerman, C.; Krut, R.; Lunsford, K.; McLeod, S.; Null, S.; Rogers, P.; Stansell, A., editors. Traditions of writing research. New York: Taylor \& Frances/ Routledge; 2010. p. 166-180.

Hayes, JR.; Flower, L. Identifying the organization of writing processes. In: Gregg, L.; Steinberg, E., editors. Cognitive processes in writing: An interdisciplinary approach. Hillsdale, NJ: Erlbaum; 1980. p. 3-30.

Hayes JR, Flower L. On the structure of the writing process. Topics in Language Disorders. 1987; 7(4):19-30.10.1097/00011363-198709000-00004

Hiebert EH. Preschool children's understanding of written language. Child Development. 1978; 49:1231-1234.10.2307/1128767

Hiebert EH. Developmental patterns and interrelationships of preschool children's print awareness. Reading Research Quarterly. 1981; 16:236-260.10.2307/747558

Hooper SR, Roberts JE, Nelson L, Zeisel S, Fannin DK. Preschool predictors of narrative writing skills in elementary school children. School Psychology Quarterly. 2010; 25(1):1-12.10.1037/a0018329

Juel C. Learning to reading and write: A longitudinal study of 54 children from first through fourth grades. Journal of Educational Psychology. 1988; 80(4):437-447.10.1037/0022-0663.80.4.437

Juel C, Griffith PL, Gough PB. Acquisition of literacy: A longitudinal study of children in first and second grade. Journal of Educational Psychology. 1986; 78(4):243255.10.1037/0022-0663.78.4.243

Justice LM, Pence K, Bowles R, Wiggins AK. An investigation of four hypotheses concerning the order by which 4-year-old children learn the alphabet letters. Early Childhood Research Quarterly. 2006; 21(3):374-389.10.1016/j.ecresq.2006.07.010

Levin I, Both-De-Vries D, Aram D, Bus A. Writing starts with own name writing: From scribbling to conventional spelling in Israeli and Dutch children. Applied Psycholinguistics. 2005; 26(3):463477.10.1017/S0142716405050253

Levin I, Bus A. How is emergent writing based on drawing? Analysis of children's products and their sorting by children and mothers. Developmental Psychology. 2003; 39(5):891905.10.1037/0012-1649.39.5.891 [PubMed: 12952401]

Levin I, Shatil-Carmon S, Asif-Rave O. Learning of letter names and sounds and their contribution to word recognition. Journal of Experimental Child Psychology. 2006; 93(2):139-165.10.1016/j.jecp. 2005.08.002 [PubMed: 16249004]

Lomax R, McGee L. Young children's concepts about print and reading: Toward a model of work reading acquisition. Reading Research Quarterly. 1987; 22(2):237-256.10.2307/747667

Lonigan, CJ.; Schatschneider, C.; Westberg, L. Report of the National Early Literacy Panel. 2008. Results of the National Early Literacy Panel research synthesis: Identification of children's skills and abilities linked to later outcomes in reading, writing, and spelling.

Lonigan, CJ.; Wagner, RK.; Torgesen, JK.; Rashotte, C. Test of Preschool Early Literacy. Austin, TX: ProEd; 2007.

Mason JM. When children begin to read: An exploration of four year old children's letter and word reading competencies. Reading Research Quarterly. 1980; 15(2):203-227.10.2307/747325 
Mason, JM.; Stewart, JP. Emergent literacy assessment for instructional use in kindergarten. In: Morrow, LM.; Smith, JK., editors. Assessment for instruction in early literacy. Englewood Cliffs, NJ: Prentice Hall; 1990. p. 155-175.

McBride-Chang C. The development of invented spelling. Early Education and Development. 1998; 9(2):147-160.10.1207/s15566935eed0902_3

McCutchen, D. Cognitive factors in the development of children's writing. In: MacAuthur, C.; Graham, S.; Fitzgerald, J., editors. Handbook of writing research. New York: Guilford; 2006. p. 115-130.

Molfese VJ, Beswick JL, Jacobi-Vessels JL, Armstrong NE, Culver BL, White JM. Evidence of alphabetic knowledge in writing: Connections to letter and word identification skills in preschool and kindergarten. Reading and Writing: An Interdisciplinary Journal. 2011; 24(2):133$150.10 .1007 / \mathrm{s} 11145-010-9265-8$

Molfese VJ, Beswick JL, Molnar A, Jacobi-Vessels JL. Alphabetic skills in preschool: A preliminary study of letter naming and letter writing. Developmental Neuropsychology. 2006; 29(1):519.10.1207/s15326942dn2901_2 [PubMed: 16390286]

Phillips BM, Piasta SB, Anthony JL, Lonigan CJ, Francis DJ. IRTs of the ABCs: Children's letter name acquisition. Journal of School Psychology. 2012; 50(4):461-481.10.1016/j.jsp.2012.05.002 [PubMed: 22710016]

Puranik CS, Al Otaiba S. Examining the contribution of handwriting and spelling to written expression in kindergarten children. Reading and Writing: An Interdisciplinary Journal. 2012; 25(7):15231546.10.1007/s11145-011-9331-x

Puranik CS, Lombardino LJ, Altmann LJP. Assessing the microstructure of written language using a retelling paradigm. American Journal of Speech-Language Pathology. 2008; 17(2):107120.10.1044/1058-0360(2008/012) [PubMed: 18448599]

Puranik CS, Lonigan CJ. From scribbles to scrabble: Preschool children's developing knowledge of written language. Reading and Writing: An Interdisciplinary Journal. 2011; 24(5):567589.10.1007/s11145-009-9220-8

Puranik CS, Lonigan CJ, Kim Y. Contributions of emergent literacy skills to name writing, letter writing, and spelling in preschool children. Early Childhood Research Quarterly. 2011; 26(4):465474.10.1016/j.ecresq.2011.03.002 [PubMed: 21927537]

Puranik CS, Petscher Y, Lonigan CJ. Dimensionality and reliability of letter writing in 3- to 5-year-old preschool children. Learning and Individual Differences. 2012 Advance online publication. 10.1016/j.lindif.2012.06.011

Robins, S.; Treiman, R. Learning to write begins informally. In: Aram, D.; Korat, O., editors. Literacy Development and Enhancement across Orthographies and Cultures, Literacy Studies 101. USA: Springer; 2010. p. 17-29.

Satorra A, Bentler PM. A scaled difference chi-square test statistic for moment structure analysis. Psychometrika. 2001; 66(4):507-514.10.1007/BF02296192

Sénéchal M, LeFevre J, Smith-Chant BL, Colton KV. On refining theoretical models of emergent literacy: The role of empirical evidence. Journal of School Psychology. 2001; 39(5):439460.10.1016/S0022-4405(01)00081-4

Stothard SE, Snowling M, Bishop D, Chipchase M, Kaplan C. Language-impaired preschoolers: A follow-up into adolescence. Journal of Speech, Language, and Hearing Research: JSLHR. 1998; 41(2):407-418.

Tabachnick, B.; Fidell, L. Using multivariate statistics. 5. Boston, MA: Pearson Education, Inc; 2007.

Tangel DM, Blachman BA. Effect of phoneme awareness instruction on kindergarten children's invented spelling. Journal of Reading Behavior. 1992; 24(2):233-261.

Tolchinsky, L. The cradle of culture and what children know about writing and numbers before being taught. Mahwah, N.J: Erlbaum; 2003.

Tolchinsky-Landsmann L, Levin I. Writing in preschoolers: An age-related analysis. Applied Psycholinguistics. 1985; 6(3):319-339.10.1017/S0142716400006238

Treiman R, Kessler B. Learning to use an alphabetic writing system. Language Learning and Development. 2013; 9(4):317-330.10.1080/15475441.2013.812016 [PubMed: 24077986] 
Treiman R, Kessler B, Pollo T. Learning about the letter name subset of the vocabulary: Evidence from U.S. and Brazilian preschoolers. Applied Psycholinguistics. 2006; 27(2):211-227.10.1017/ S0142716406060255

Wagner RK, Puranik CS, Foorman B, Foster L, Gehron L, Tschinkel E, Kantor P. Modeling the development of writing. Reading and Writing: An Interdisciplinary Journal. 2011; 24(2):203220.10.1007/s11145-010-9266-7

Wagner RK, Torgesen JK, Rashotte CA, Hecht SA, Barker TA, Burgess SR. Changing relations between phonological processing abilities and word-level reading as children develop from beginning to skilled readers: A 5-year longitudinal study. Developmental Psychology. 1997; 33(3): 468-479.10.1037/0012-1649.33.3.468 [PubMed: 9149925]

Wagner RK, Torgesen JK, Rashotte CS. Development of reading-related phonological processing abilities: New evidence of bidirectional causality from a latent variable longitudinal study. Developmental Psychology. 1994; 30(1):73-87.10.1037/0012-1649.30.1.73

Wechsler, D. Wechsler Preschool and Primary Scale of Intelligence-III. San Antonio, TX: Psychological Corporation; 2002.

Welsh JG, Sullivan A, Justice LM. That's my letter! What preschoolers' name writing representations tell us about emergent literacy knowledge? Journal of Literacy Research. 2003; 35(2):757776.10.1207/s15548430jlr3502_4

Whitaker D, Berninger VW, Johnston J, Swanson LH. Intraindividual differences in levels of language in intermediate grade writers: Implications for the translating process. Learning and Individual Differences. 1994; 6(1):107-130.10.1016/1041-6080(94)90016-7

Whitehurst GJ, Lonigan CJ. Child development and emergent literacy. Child Development. 1998; 69(3):848-872.10.1111/j.1467-8624.1998.tb06247.x [PubMed: 9680688] 


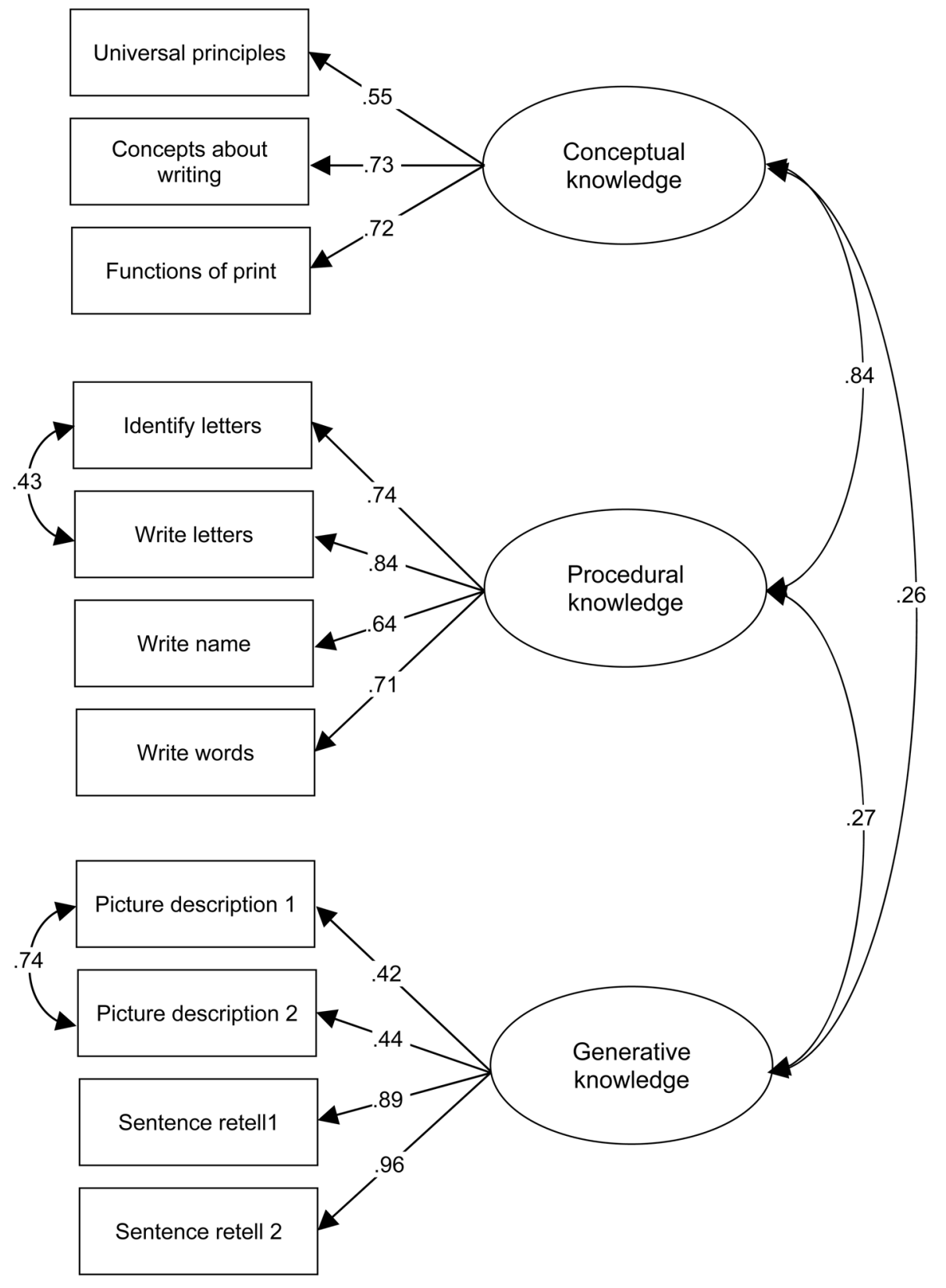

Figure 1.

Three-Factor Model of Emergent Writing-related Abilities. 


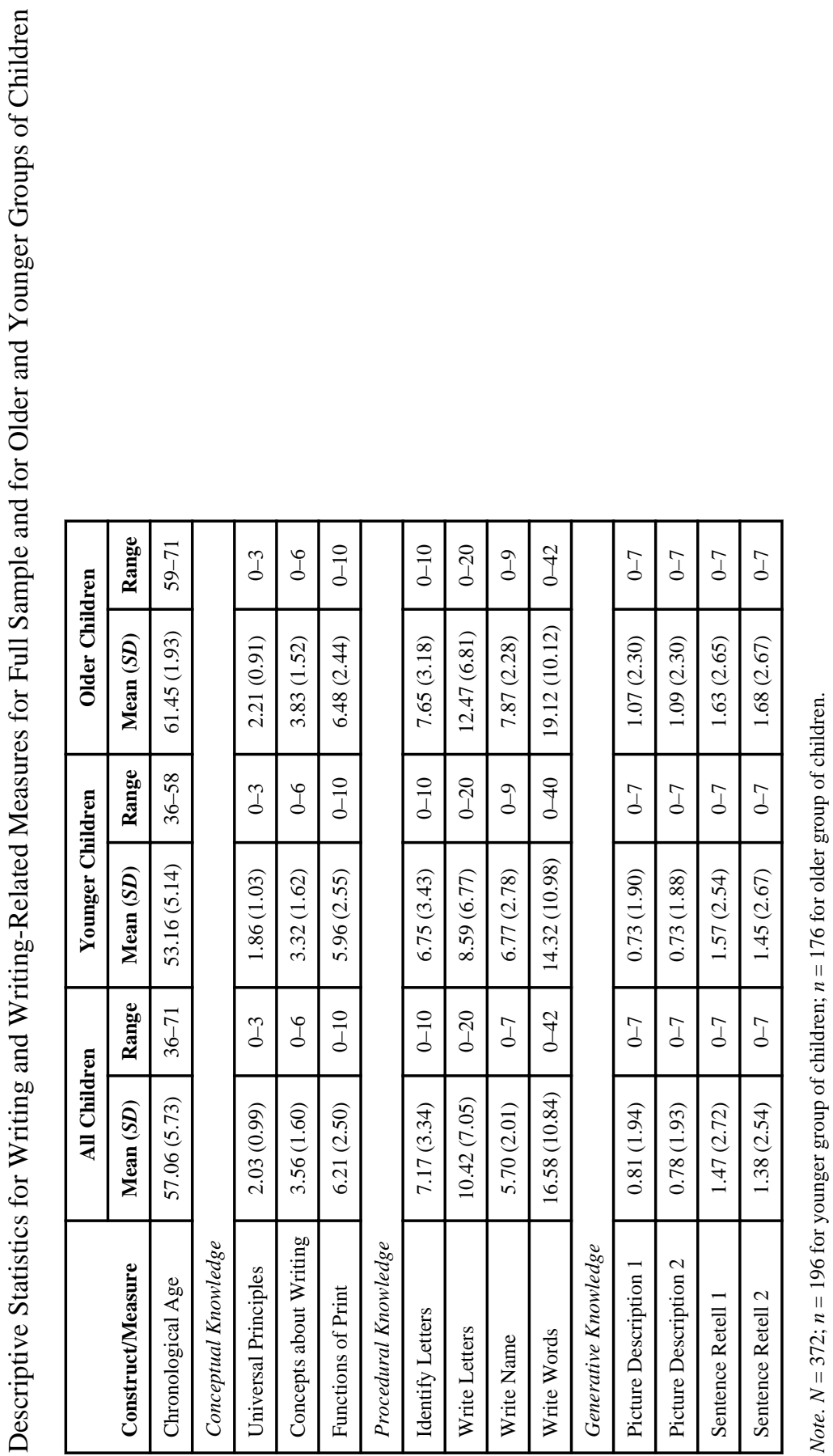




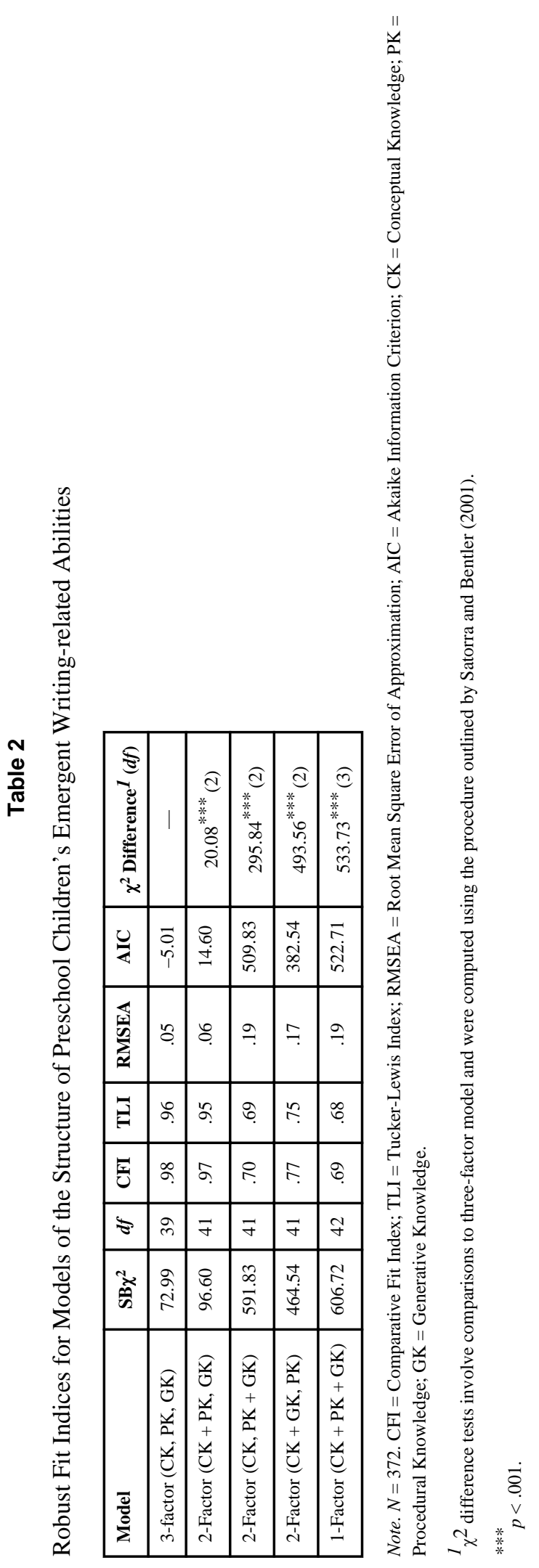

Read Res Q. Author manuscript; available in PMC 2015 October 01. 


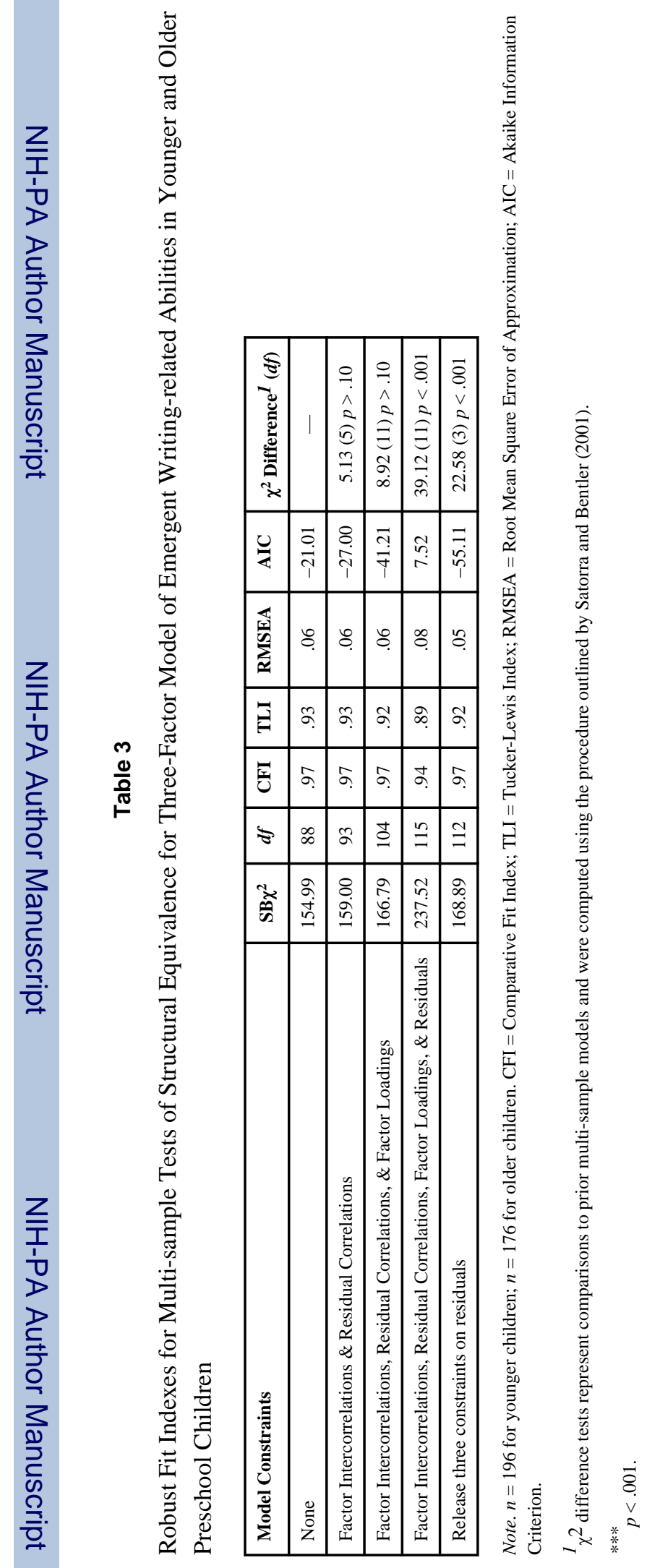

Read Res Q. Author manuscript; available in PMC 2015 October 01. 


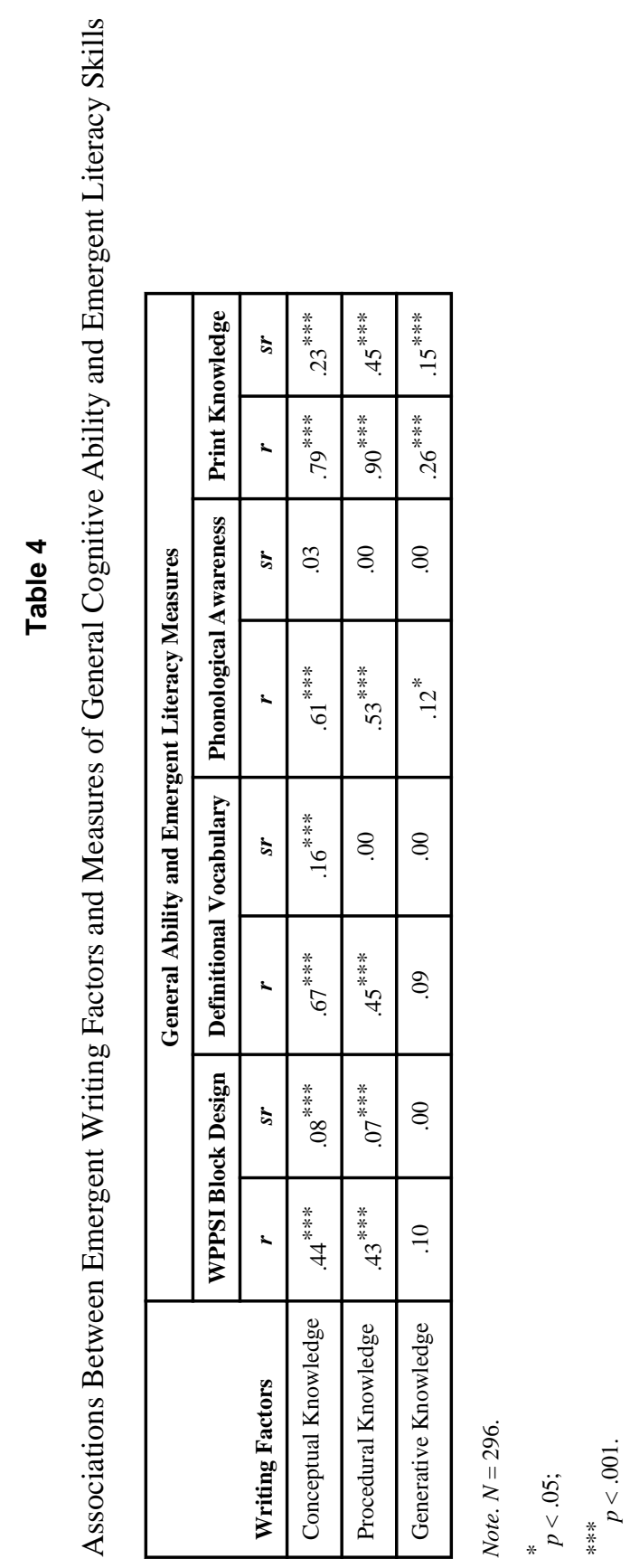

Read Res Q. Author manuscript; available in PMC 2015 October 01. 